\title{
Evaluation of the implementation of advanced nursing competencies in the Basque health care system
}

\author{
Galder Abos-Mendizabal, Roberto Nuño-Solinis, Leticia San Martin-Rodriguez \\ Basque Institute for Healthcare Innovation (O+Berri), Sondika, Bizkaia \\ Correspondence: Galder Abos-Mendizabal. Address: Plaza de Asua no 1, 48150, Sondika, Bizkaia. Telephone: 34- \\ 688-800-117. Email: galder@bioef.org.
}

Received: October 9, 2012

Accepted: December 4, 2012

Online Published: February 25, 2013

DOI : $10.5430 /$ jnep.v3n9p23

URL: http://dx.doi.org/10.5430/jnep.v3n9p23

\begin{abstract}
In 2011 advanced competences in nursing were defined and pilot tested in the Basque Healthcare System, in order to meet the needs of chronic patients. It is assumed that nursing professionals, in a functional sense, can fulfil a liaison role both within the health system and with external stakeholders. Integration between levels of care, the mobilisation of resources and case management are fundamental factors in achieving this objective.

Background: In 2010, an overall strategy for tackling the challenge of chronicity was launched in the Basque Country. Its main objective was to drive the Basque Health Service (Osakidetza) towards improving care for patients with chronic illnesses (Department of Health and Consumer Affairs, Basque Government and Osakidetza, 2010). Under this strategy, there was a commitment to develop and implement advanced competencies in nursing, with the objective of introducing nursing roles to better meet the needs of chronic patients.
\end{abstract}

Methods: To achieve this objective, a one-group pre-test and post-test pre-experimental design was adopted for this study. We used the SATISFAD questionnaire to assess the satisfaction of patients and caregivers, and the SF-12 and Barthel Index to measure quality of life and level of independence respectively.

Results: The experience of introducing the new nursing competencies has been rated as very positive by the participating patients and those around them (their caregivers and families) as it is perceived to have resulted in care that is more personalised, better planned and focused on the patient than traditional healthcare.

Nevertheless, the process was not found to have significantly improved patient perception of quality of life and level of independence.

Conclusions: The implementation of advanced competencies in the Basque Country has shown that case management leads to improvements in social and health care for patients, and their caregivers and families, compared to traditional care.

\section{Key words}

Basque Country, Primary care, Advanced competencies, Nurse, Chronic patient, Case management

\section{I ntroduction}

Chronic conditions have an impact on individuals as they represent a restraint on quality of life, functional status, and productivity of people who suffer from them but they also compromise the sustainability of health systems. In 2010, the 
Strategy for Tackling the Challenge of Chronicity in the Basque Country was published (Basque Department of Health and Consumer Affairs and Osakidetza ${ }^{[1]}$. It contains policies and projects aimed at reinventing the health delivery model with the purpose of improving the quality of care for chronic patients and advancing toward a more sustainable, proactive, and integrated model ${ }^{[2]}$.

Under this strategy, a commitment was made to develop and implement advanced competences in nursing, with the objective of introducing nursing roles that meet the needs of chronic patients. It is assumed that nursing professionals, in a functional sense, can fulfil a liaison role both within the health system and with external stakeholders. Integration between levels of care, the mobilisation of resources and case management are fundamental factors in achieving this objective.

To define these new roles, a working group was set up with involvement of professionals from all levels of Osakidetza and from other institutions (the College of Nursing, nursing faculties, etc.). On the basis of the literature available at the time on best practice both nationally and internationally in relation to chronic care and nursing roles, and viewing this in the context of the Basque Health Service, the group defined three new nursing roles to be introduced.

The three roles revolve around the concept of "case management" applied to the case of complex patients with multiple chronic illnesses. Case management is based on the assumption that individuals with complex health problems need help to use the health system effectively ${ }^{[3]}$. By definition, a nurse case manager implements, coordinates, monitors and evaluates options and services in order to cover a patient's needs, through communication and identifying the necessary resources to promote high-quality, cost-effective outcomes ${ }^{[4]}$. The more specific characteristics of the three roles defined are the following:

- Nurse manager for advanced competencies (NMAC): case management and coordination of primary, specialist and social services through the provision of personalised care for complex patients with multiple conditions who require home care.

- Nurse manager for continuity (NMC): case management and coordination of primary, specialist and social services through the provision of personalised care for complex patients with multiple conditions who do not require home care.

- Hospital liaison nurse (HLN): case management and coordination of inpatient care for complex patients with multiple conditions coordinating with the corresponding primary care case manager (NMAC and NMC, depending on the case) for transfers of patients to and from their home.

It was decided that the three roles should be introduced in parallel, creating two different models of care. The HLN, responsible for case management and coordination of care within the hospital and with primary care, is involved in both models, working together with the NMAC in one of the models and the NMC in the other. While both the NMAC and the NMC are case managers and responsible for coordination with primary, specialist and social services for the delivery of personalised care, the roles differ mainly in that the NMAC and NMC are focused on complex patients that do and do not require home care respectively.

It should be emphasized that all three roles require a proactive effort within their sphere of operation to identify suitable patients in collaboration with their corresponding work teams (primary and specialist) and the team of the strategic project for population stratification and targeting set up by the Department of Health and Consumer Affairs of the Basque Government.

The selection criteria applied by the nurses for identifying patients were the following: being over 65 years of age, with a history of one or more hospital admission in the previous year, and diagnosed with or taking medication that implied they have congestive heart failure or chronic obstructive pulmonary disease. These criteria were allowed to be adjusted slightly and/or new criteria added in response to the real circumstances in each health centre and/or hospital where the roles were 
introduced. Individuals who were institutionalised in residential facilities as well as those on dialysis or who had cancer were excluded.

It was decided to evaluate the implementation of both the models on the basis of the satisfaction of patients and caregivers with the care received and patient level of dependence in the performance of activities of daily living. Specifically, the main objective of this study was to describe the level of satisfaction of patients and caregivers and assess changes in the quality of life and level of independence of patients cared for under the two models introduced by these three new nursing positions.

\section{Patients and methods}

To achieve the objective of the study, a one-group pre-test and post-test pre-experimental design ${ }^{[5]}$ was used.

\subsection{Sample and sampling}

The sample comprised 330 patients. Convenience sampling was used, meaning that all patients who agreed to participate in the study and met the inclusion criteria were included in the intervention group until we had recruited the aforementioned number of individuals. The criteria for inclusion and exclusion were the same as the aforementioned criteria applied by the nurse managers for selecting patients. Specifically, patients were eligible if they were over 65 years of age, with a history of one or more hospital admission in the previous year, and diagnosed with or taking medication that implied they have congestive heart failure or chronic obstructive pulmonary disease; and were excluded if institutionalized in residential facilities, on dialysis or diagnosed with cancer.

\subsection{Intervention}

The new roles were piloted for 8 months in 2011 in 8 different settings (including both rural and urban centres) fine tuning the job description to meet the needs the population and services in each case and including various types of coordination between primary and specialist care (hospitals, health centres and home care) involving around 1000 Healthcare professionals in one way or another.

All the nurses in these roles provided personalized case management for a list of patients proactively identified in their field of operation, including coordination between primary, secondary and social care as well as that of caregivers themselves. In the case of the NMAC, it's necessary to make emphasis on that they also provide home care to selected patients.

\subsection{Measurement instruments}

The level of satisfaction was assessed using a 10-item questionnaire based on the home care satisfaction questionnaire SATISFAD, 8 items assessing satisfaction from the perspective of the patient and 2 from that of the caregiver. These items assessed, on the one hand, the views of the patient on the organization of their care as well as the care they actually received and, on the other, the way the caregivers view their participation in the organization of the care and any changes in their role as career. Responses are given on a 4-point Likert scale, on which 1 corresponds to the lowest level of satisfaction and 4 the highest.

To assess quality of life, we used a version of the short form health survey SF-12 translated into Spanish and adapted by Alonso et al. ${ }^{[6]}$, Vilagut et al ${ }^{[7]}$. It is composed of 12 items that assess physical functioning (2 items), social functioning (1 item), physical and emotional role limitations (2 items each), mental health (2 items, vitality, bodily pain and general health (1 item each). The frequency or severity of problems is rated on a Likert scale with the number of response options varying by item, from three to six. 
Lastly, the level of independence was measured using the Barthel Index ${ }^{[8]}$, which can be used to classify the patient into one of five levels (independent; or mildly, moderately, severely or totally dependent) in accordance with the score obtained in the assessment of their performance of 10 basic activities of daily living: feeding, washing, dressing, personal grooming, control of bowels and bladder, getting on and off the toilet, moving from chair to bed and back, walking, and going up and down stairs. The total score ranges from 0 (totally dependent) to 100 (independent). The scale been shown to have good reliability and validity ${ }^{[9]}$.

\subsection{Data collection procedure}

On the one hand, the data concerning patient and caregiver satisfaction and quality of life were obtained by telephone interviews, conducted before and, in the case of the quality of life, also after the intervention. On the other hand, the assessment of patient independence both before and after the intervention was completed by the corresponding nurse. Lastly, sociodemographic data were collected from the centralized patient database.

\subsection{Data analysis}

For the descriptive analysis, we used measures of central tendency and dispersion for the quantitative data (mean and SD, or median and maximum and minimum, depending on the distribution of the data), and frequencies and percentages for the qualitative data. On the other hand, we compared data on quality of life before and after the intervention with the Student's $t$-test, while levels of independence were compared with the Wilcoxon test.

The analysis was performed using SPSS (version 14.0), with the level of significance set at 0.05 in all cases.

\section{Results}

The mean age of the patients who participated in the study was 77 years, and $61 \%$ were men. All individuals in the study population were assigned to one of six levels of comorbidity, so-called resource utilization bands (RUBs) (The Johns Hopkins ACG ${ }^{\circledR}$ System Reference Manual ${ }^{[10]}$ ). The population in RUB 0 has no need for health care and those in RUB 5 have a very high degree of need for health care resources. The data for our sample are shown in Table 1, 39\% of patients being categorised into RUB 5, that is, users with high morbidity.

Table 1. Description of the sample

\begin{tabular}{ll}
\hline Descriptive data & \% \\
\hline Sex & 61 \\
men & 39 \\
women & \\
Resource utilization band (RUB) & 2 \\
RUB 1 & 3 \\
RUB 2 & 29 \\
RUB 3 & 27 \\
RUB 4 & 39 \\
RUB 5 & \\
\hline
\end{tabular}

The mean score for patient-reported satisfaction was $3.86(\mathrm{SD}=0.3$ ), while the mean score for caregiver satisfaction was $3.65(\mathrm{SD}=0.7)$, in both cases out of a maximum of 4 points.

Table 2 lists the mean pre- and post-test quality of life scores obtained on each of the dimensions. The t-test indicated that quality of life was rated as significantly better after the intervention with respect to physical functioning $(p=0.010)$ and general health $(p=0.009)$, but significantly poorer in terms of physical role limitations $(p=0.037)$, mental health $(p=0.001)$ 
and vitality $(p=0.000)$. There were no significant differences in pre- and post-test scores in the other dimensions (in all cases $p>0.05)$.

Table 2. Mean quality of life scores by dimension

\begin{tabular}{lllllllll}
\hline Scores & $\begin{array}{l}\text { Physical } \\
\text { functioning }\end{array}$ & $\begin{array}{l}\text { Social } \\
\text { functioning }\end{array}$ & $\begin{array}{l}\text { Role - } \\
\text { physical }\end{array}$ & $\begin{array}{l}\text { Role - } \\
\text { emotional }\end{array}$ & $\begin{array}{l}\text { Mental } \\
\text { health }\end{array}$ & Vitality & $\begin{array}{l}\text { Bodily } \\
\text { pain }\end{array}$ & General health \\
\hline Pre-test & 1.38 & 2.99 & 1.38 & 1.61 & 3.79 & 3.16 & 1.71 & 1.79 \\
Post-test & 1.56 & 2.96 & 1.28 & 1.65 & 3.47 & 2.62 & 1.58 & 2.05 \\
Difference & 0.18 & -0.03 & -0.10 & 0.04 & -0.32 & -0.54 & -0.13 & 0.26 \\
\hline
\end{tabular}

Table 3. Distribution of patients by level of independence

\begin{tabular}{lll}
\hline & Pre-test (\%) & Post-test (\%) \\
\hline Independent & 37.8 & 24.1 \\
Mildly dependent & 38.1 & 36.2 \\
Moderately dependent & 12.2 & 18.9 \\
Severely dependent & 6.8 & 8.2 \\
Totally dependent & 5.0 & 12.6 \\
\hline
\end{tabular}

As for patient level of independence, Table 3 shows the percentages of patients in each category before and after the intervention. Comparison of the pre- and post-test levels with the Wilcoxon test indicates that in $68 \%$ of cases the patient's level of independence did not change, while $30 \%$ had become less independent and $2 \%$ more independent after the intervention. These differences are statistically significant $(p=0.000)$.

\section{Discussion}

First, we should underline that the experience of implementing the new nursing competencies was rated as very positive by the patients who participated and those around them (their caregivers and families) as it was perceived to have resulted in care that is more personalized, better planned and focused on the patient than traditional healthcare. Further, the involvement of patients and their caregivers and families in the development and implementation of personal care plans (as well as encouragement for self-care and training in the necessary skills) achieved a high level of acceptance and understanding by these individuals of the care provided while improving its effectiveness.

Patients rated both the organization and quality of care received directly very positively. Additionally, the caregivers reported a high level of satisfaction with the impact of the new nurse managers on their role as carers and with the fact that they had been able to participate in decisions about the organization of care.

On the other hand, while the results indicate that after the intervention quality of life was better in relation to general health and physical functioning, patients obtained poorer scores for physical role limitations, mental health and vitality. That is, patients felt that their overall quality of life and their physical ability to walk or climb stairs had improved, but despite this improvement in physical functioning, they had a perception of it being more difficult to do their work and perform daily activities, as well as reporting a more depressed mood and less vitality.

In relation to this, in a review, Latour et al ${ }^{[11]}$ pointed out that, while they had expected to find an improvement in quality of life and psychological functioning in patients under the care of nurse case managers, this expectation was not borne out by the results in the various studies available. According to these authors, the results could be attributable to patients with nurse case managers, given the education and training provided by these nurses, being more aware of their vulnerability and limitations, and that this has a negative impact on their perception of their abilities and functioning. 
Lastly, our data show that $68 \%$ of patients had the same level of independence in the pre- and post-intervention periods, while in $30 \%$ of cases they became more dependent and $2 \%$ less dependent. This could be explained by the characteristics of the sample. As can be seen from the descriptive statistics, the patients who participated in this study were of advanced age with high morbidity while, in contrast, they were relatively independent at the outset. Hence, it is reasonable to suggest that there was little margin for improvement in levels of independence among these patients.

The results obtained in the different geographical settings tested where similar with slight variations according to all the variables measured. Taking in account that the starting point for the different locations where this roles were pilot tested was so different from dispersion (Rural Vs Urban) and social status perspective, obtained results seem to be consistent across the different pilot tests. On the other hand, we consider that the number of patients and health care professionals involved in the experience is determinant in order to validate or not achieved results. In this case, immense majority of the 330 patients have similar results even-though they live and belong to different social and geographical environments as we underlined before.

Furthermore, the results obtained in our project are also consistent with pilot studies in this field in other parts of the world and research on the impact of case managers on patients and caregivers. These include the review of case management by Lupari et al ${ }^{[12]}$ and studies by MacAdam and Mckenzie ${ }^{[13]}$, Hébert et al. ${ }^{[14]}$ and Morales et al. ${ }^{[15]}$ among others.

\section{Conclusion}

The introduction of advanced nursing competencies in the Basque Country has been shown to significantly improve the satisfaction of patients involved in the project as well as their caregivers, while, consistent with the nature of the target population for this type of programme, the perception of these patients of their quality of life and level of independence follows a trend that reflects the progression of their diseases.

It should be highlighted that it was, nevertheless, possible to improve levels of independence and quality of life in some cases, particularly those in which patients' social and health care needs were not well met at the outset. In these cases, the proactive identification of candidate patients by nurses with advanced competencies enabled highly vulnerable, neglected individuals to be detected and measures to be taken to normalize their situation.

Overall, the development of advanced nursing competencies in the Basque Country was found to be having a similar effect to that observed in projects in other parts of the world, in terms of the variables considered in this paper. Specifically, it can be concluded that case management improves social and health care for the patient and those around them compared to conventional care.

\section{Limitations}

Pilot test experience duration was 8 months, which could be not enough time in order to let the activity of the nurses have a significant impact on selected patients.

On the other hand, not having a control Group to contrast with could be a limitation in order to completely validate achieved results. From a theoretical perspective, there could exist different elements to the tested ones during the intervention that could affect to achieved results ${ }^{[16]}$. However, as this project was tested in different geographical regions (including both rural and urban centres), with different healthcare professionals, the chances to find different results to the achieved ones decrease. 


\section{Acknowledgement}

The authors thank Inmaculada Sánchez Martin (Director of Nursing in Osakidetza and leader of the project), Ana María Chueca (Methodology Unit at Galdakao-Usansolo Hospital), Maria Angeles Cidoncha (Director of Nursing Teaching and Research in Osakidetza), Rosa González (Office for the Chronicity Strategy, OEC), María Luz Peña (nurse in the Subdepartment for Healthcare), María Jesús Ruiz de Ocenda (Ex-Director of Nursing in Osakidetza and previous leader of the project), Javier Bikandi (Senior Researcher at O+Berri) and Naiara Artaza (Head of Prospective at O+berri).

This project was funded by the Department of Health and Consumer Affairs of the Basque Government, Basque Health Service (Osakidetza), Basque Institute for Healthcare Innovation (O+Berri), and Centre of Excellence in Research on Chronicity (Kronikgune).

\section{References}

[1] Departamento de Sanidad y Consumo del Gobierno Vasco y Osakidetza.Estrategia para afrontar el reto de la cronicidad en Euskadi. Gobierno Vasco; 2010. Available from: http://cronicidad.blog.euskadi.net/descargas/plan/EstrategiaCronicidad.pdf.

[2] Nuño-Solinís R, Orueta JF, Mateos M. 2012. An answer to chronicity in the Basque Country: primary care-based population health management. J Ambul Care Manage. 2012 Jul-Sep; 35(3): 167-73. PMid:22668605

[3] Lee D T, Mackenzie A.E, Dudley-Brown S, Chin T. M. Case management: a review of the definitions and practices. Journal of Advanced Nursing. 1998; 27(5): 933-937. PMid:9637319 http://dx.doi.org/10.1046/j.1365-2648.1998.t01-1-00566.x

[4] Glettler E, \& Leen M. The advanced practice nurse as case manager. Journal of Case Management. 1996; 5(3): 121-126. PMid:9257627

[5] Health Services Research \& Development Center at Johns Hopkins University, Bloomberg School of Public Health: The Johns Hopkins ACG® System Reference Manual. Version 8.2. Baltimore, MD; 2008

[6] Alonso J, Regidor E, Barrio G, Prieto L, Rodríguez C, \& De la Fuente L. 1998. Valores poblacionales de referencia de la versión española del Cuestionario de Salud SF-36. Medicina Clinica Barcelona. 1998; 111: 410-416.

[7] Vilagu, G., Ferrer M., Rajmil M, Rebollo P., Permanyer-Miralda G, Quintana J. M, Santed R, Valderas J. M, Ribera, A, Domingo-Salvany A, \& Alonso J. El cuestionario de salud SF-36 español: una década de experiencia y nuevos desarrollos. Gaceta Sanitaria. 2005; 19(2): 135-150.

[8] Mahoney F. I, \& Barthel D. W. Functional evaluation: the Barthel Index. Maryland Medical Journal. 1965; 14: 61-65.

[9] Cid-Ruzafa J, \& Damián-Moreno J. Valoración de la discapacidad física: el índice de Barthel. Revista Española de Salud Publica. 1997; 71(2): 127-137. PMid:9546856 http://dx.doi.org/10.1590/S1135-57271997000200004

[10] Health Services Research \& Development Center at Johns Hopkins University, Bloomberg School of Public Health: The Johns Hopkins ACG® System Reference Manual. Version 8.2. Baltimore, MD; 2008.

[11] Latour C, Bosmans M, Van Turlder M, et al. Cost-effectiveness of a nurse-led case management intervention in general medical outpatients compared with usual care: An economic evaluation alongside a randomized controlled trial. Journal of Psychosomatic Research. 2007; 62: 363-370. PMid:17324688 http://dx.doi.org/10.1016/j.jpsychores.2006.10.016

[12] Lupari M, Coates V, Adamson G, Crealey GE. 'We're just not getting it right'--how should we provide care to the older person with multi-morbid chronic conditions? J Clin Nurs. 2011 May; 20(9-10): 1225-35. http://dx.doi.org/10.1111/j.1365-2702.2010.03620.x

[13] MacAdam M, MacKenzie S. “System Integration in Quebec: The Prisma Project”. Health Policy Monitor. 2008. Available from: http://www.hpm.org/Downloads/HPM_SPOTLIGHTS/Canada_Improving_care_for_the_frail_elderly__the_PRISMA_project. pdf

[14] Hébert R, Durand S, Somme D, Raîche M. PRISMA in Québec and France: implementation and impact of a coordination-type integrated service delivery (ISD) system for frail older people International Journal of Integrated Care - Vol. 9, 31 December 2009

[15] Morales-Asencio JM, Gonzalo-Jiménez E, Martin-Santos FL, Morilla-Herrera JC, Celdráan-Mañas M, Millán Carrasco. http://www.biomedcentral.com/1472-6963/8/193/-ins3 A, García-Arrabal JJ, Toral-López.

http://www.biomedcentral.com/1472-6963/8/193/ - ins5 I. Effectiveness of a nurse-led case management home care model in Primary Health Care. A quasi-experimental, controlled, multi-centre study. BMC Health Services Research. 2008; 8: 193 PMid:18811927 http://dx.doi.org/10.1186/1472-6963-8-193

[16] Campbell D, \& Stanley J. C. 2011. Diseños experimentales y cuasiexperimentales en la investigación social (2ª ed). Buenos Aires: Amorrortu. 